\title{
Activation-Induced Cytidine Deaminase is A Possible Regulator of Cross-Talk Between Oocytes and Granulosa Cells Through GDF-9 and SCF Feedback System
}

\section{Takashi lizuka}

Kanazawa University

Kousho Wakae

National Institute of Infectious Diseases

Takuma Suzuki

Kanazawa University

Masanori Ono

Kanazawa University

Koichi Kitamura

National Institute of Infectious Diseases

Shin-ichi Horike

Kanazawa University

Masamichi Muramatsu

National Institute of Infectious Diseases

Hiroshi Fujiwara ( $\nabla$ fuji@med.kanazawa-u.ac.jp )

Kanazawa University

\section{Research Article}

Keywords: AID, folliculogenesis, GDF-9, granulosa cell, oocyte, SCF

Posted Date: November 24th, 2020

DOl: https://doi.org/10.21203/rs.3.rs-107061/v1

License: (c) (i) This work is licensed under a Creative Commons Attribution 4.0 International License.

Read Full License

Version of Record: A version of this preprint was published at Scientific Reports on February 15th, 2021.

See the published version at https://doi.org/10.1038/s41598-021-83529-x. 

1 Activation-induced cytidine deaminase is a possible regulator of cross-talk between oocytes and granulosa cells through GDF-9 and SCF feedback system

4 Takashi Iizuka $^{1}$, Kousho Wakae ${ }^{2}$, Masanori Ono ${ }^{1}$, Takuma Suzuki ${ }^{1}$, Koichi Kitamura ${ }^{2}$, Shin-

5 ichi Horike ${ }^{3}$, Masamichi Muramatsu*2, and Hiroshi Fujiwara*1

6

$7 \quad{ }^{1}$ Department of Obstetrics and Gynecology, Graduate School of Medical Sciences,

8 Kanazawa University, Kanazawa, Japan

$9 \quad{ }^{2}$ Department of Virology II, National Institute of Infectious Diseases, Tokyo, Japan,

$10 \quad{ }^{3}$ Advanced Science Research Center, Kanazawa University, Kanazawa, Japan

12 Abbreviated title: AID modulates ovarian GDF-9 and SCF system

14 Key words: AID; folliculogenesis; GDF-9; granulosa cell; oocyte; SCF

*Address correspondence to

17 Hiroshi Fujiwara, MD, PhD

18 Department of Obstetrics and Gynecology, Graduate School of Medical Sciences, Kanazawa

19 University, Takara-machi 13-1, Kanazawa, Ishikawa 920-8640, Japan

20 Tel.: +81-76-265-2425, Fax: +81-76-234-4266, E-mail: fuji@med.kanazawa-u.ac.jp

21 Masamichi Muramatsu, MD, PhD

22 Department of Virology II, National Institute of Infectious Diseases, Tokyo 162-8640, Japan 23 Tel.: +81-03-5285-1111, Fax: +81-03-5285-1150, E-mail: muramatsu@nih.go.jp

25 Disclosure Statement: The authors have nothing to disclose. 


\section{Abstract}

Activation-induced cytidine deaminase (AID, Aicda) is a master gene regulating

3 class switch of immunoglobulin genes. In this study, we investigated the significance of AID

4 expression in the ovary. Immunohistological study and RT-PCR showed that AID was

5 expressed in murine granulosa cells and oocytes. However, using the Aicda-Cre/Rosa-tdRFP

6 reporter mouse, its transcriptional history in oocytes was not detected, suggesting that AID

7 mRNA in oocytes has an exogenous origin. Microarray and qPCR validation revealed that

8 mRNA expressions of growth differentiation factor-9 (GDF-9) in oocytes and stem cell factor

9 (SCF) in granulosa cells were significantly decreased in AID-knockout mice compared with

10 wild-type mice. A 6-hour incubation of primary granuloma cells markedly reduced AID

11 expression, whereas it was maintained by recombinant GDF-9. In contrast, SCF expression

12 was induced by more than 3-fold, whereas GDF-9 completely inhibited its increase. In the

13 presence of GDF-9, knockdown of AID by siRNA further decreased SCF expression. However,

14 in AID-suppressed granulosa cells and ovarian tissues of AID-knockout mice, there were no

15 differences in the methylation of SCF and GDF-9. These findings suggest that AID is a novel

16 candidate to regulate cross-talk between oocytes and granulosa cells through a GDF-9 and

17 SCF feedback system, probably in a methylation-independent manner. 
Introduction

The apolipoprotein B mRNA editing enzyme, catalytic polypeptide-like (APOBEC)

3 family is a group of cytidine deaminases that convert cytosine (C) to uracil (U) in DNA/RNA ${ }^{1}$.

4 In humans, the APOBEC family is composed of 11 members (AID and APOBEC1, 2, 3A, 3B,

$53 \mathrm{C}, 3 \mathrm{D}, 3 \mathrm{~F}, 3 \mathrm{G}, 3 \mathrm{H}$ and 4). In mice, 4 types have been confirmed (AID and APOBEC 1 to 3 ).

6 AID is abundantly expressed in mammalian B lymphocytes, and induces genetic modification

7 in antibody genes. In B lymphocytes, AID is involved in class switching inducing DNA

8 cleavage by generating uracil in antibody genes. AID can also act on the variable region of

9 the antibody gene, inducing hypermutation and altering the affinity of the antibody for its

10 antigen ${ }^{2}$.

11 Ectopic expression of AID in non-lymphoid tissues was induced by inflammation.

12 AID leads to the accumulation of mutations and is associated with carcinogenesis in fallopian

13 tubes ${ }^{3}$, gastric mucosa ${ }^{4}$, and skin ${ }^{5}$. On the other hand, AID is expressed in normal mouse

14 ovaries $^{6-8}$, the genital ridge ${ }^{6}$, and primordial germ cells ${ }^{9}$. It has also been demonstrated that

15 the estrogen-estrogen receptor complex binds to the Aicda promoter, producing AID protein

16 both in lymphoid and non-lymphoid organs including ovaries ${ }^{10}$. Nonetheless, AID-knockout

17 (KO) mice showed no fertility abnormal phenotype ${ }^{7,8}$, and so its significance, as well as

18 distribution, remains to be determined.

Our preliminary examination confirmed that immunoreactive AID is highly expressed in cumulus granulosa cells ${ }^{7}$. Since oocytes should be protected from genetic mutation, it is curious that the mutagenic enzyme AID is present around oocytes. Recently, it was reported that follicular fluid contained extracellular vesicles (EVs) and follicular EVs

23 include granulosa cell-derived mRNA ${ }^{11}$, proposing a new mechanism for communication 24 within the ovarian follicle and the cross-talk between oocytes and cumulus granulosa cells 25 through $\mathrm{EVs}^{12-15}$. In addition, exogenously labelled-AID that was microinjected into the 
1 cytoplasm of oocytes in the germinal vesicle stage was shown to enter the nucleus of oocytes

2 just before germinal vesicle breakdown, suggesting that AID can directly access oocyte DNA

$3{ }^{16}$. Considering that AID is a candidate to play a role in epigenetic reprogramming ${ }^{6,17,18}$, it is

4 worthy examining physiological roles of AID in the cross-talk between oocytes and cumulus

5 granulosa cells. Consequently, in this study, we examined the precise expression profiles of

6 AID in the mouse ovary and investigated its possible role in ovarian functions.

8 Results

9 AID is expressed in murine oocytes and granulosa cells

First, we immunohistochemically stained murine Peyer's patches and observed that

11 AID was expressed on B lymphocytes in the Peyer's patches (Fig. 1A) ${ }^{19}$. In 8-week-old mouse

12 ovaries, AID expression was detected in the oocytes and granulosa cells in the follicles, but 13 not in the surface epithelial cells, interstitial-stromal cells, nor luteal cells in the corpus luteum 14 (Fig. 1A and 1B). The staining profiles of AID using another anti-AID antibody (Merck 15 Millipore MABF63, clone 328.8) raised against a different antigenic peptide were similar to 16 those detected with the initial antibody (Fig. 1C). The expression of AID was not observed in 17 the ovarian follicles of AID-KO mice, validating the specificity of this assay (Fig. 1C). In accordance with the results of immunohistological study, mRNA expression of 19 AID in granulosa cells and oocytes was confirmed by RT-PCR (Fig. 1D). RT-qPCR showed that the AID mRNA expression level in granulosa cells was higher than that in oocytes (Fig. 1E). Taken together, these results suggest that AID is abundantly expressed in the murine ovary, especially granulosa cells.

For further verification, we employed Aicda-Cre/Rosa-tdRFP reporter mice, where

24 the history of AID expression can be traced by tdRFP ${ }^{20}$. However, the expression of RFP was 25 observed in granulosa cells and luteal cells that are derived from granulosa cells (Fig. 2A), but 
1 not in oocytes (Fig. 2B).

\section{Down-regulated genes in the granulosa cells of AID-KO mice}

To identify the AID-regulated molecules in murine granulosa cells, microarray analysis was performed. Up-regulated genes were defined as those with a fold-change $>2$ with highly ranked genes in WAD ranking (304 genes), whereas down-regulated genes were those with a fold-change $<0.5$ (274 genes) out of a total of 27281 genes. Gene ontology biological

8 process term enrichment analyses of the identified up- and down-regulated genes were 9 performed using the Database for Annotation, Visualization and Integrated Discovery (DAVID) with the threshold set at a P-value $<0.05$, and the top five groups are presented (Fig. $113 \mathrm{~A})$.

Since the gene ontology term of regulation of reproductive process was detected in

13 the down-regulated group, we focused on the genes related to follicular formation. Among 14 them, GDF-9 (a secreted member of the transforming growth factor- $\beta$ superfamily) and SCF 15 (c-Kit ligand) were significantly down-regulated in granulosa cells of AID-KO mice. This 16 reduction was confirmed by RT-qPCR using samples different from those used for the 17 microarray (Fig. 3B). Since GDF-9 was reported to be secreted from oocytes, we also examined the mRNA expression of GDF-9 in oocytes and the immunohistological localization of GDF-9 protein in the ovary. RT-qPCR showed that the mRNA expression of GDF-9 in oocytes was high and its expression was decreased in oocytes derived from the AID-KO mouse (Fig. 3C).

22 Immunohistological examination showed that the protein expression of GDF-9 was detected 23 in oocytes and granulosa cells, whereas its expression was reduced in the AID-KO mouse (Fig. 24 3D). Taken together, these findings suggest that AID positively regulates folliculogenesis25 related genes, both in oocytes and granulosa cells. 
We also evaluated the ovarian morphology of AID-KO mice, revealing no apparent abnormality in the structure of the ovaries compared with the wild type at both 3 and 8 weeks of age (Fig. 4A and B). Since GDF-9 and SCF were reported to be involved in follicular development ${ }^{21-23}$, we counted the number of secondary follicles and early antral follicles, but there was no significant difference (Fig. 4C and D). The average litter size of AID-KO mice was 7.0 +/- 0.8, which was the same as that in the background C57/BL6 mice (data not shown).

GDF-9 promotes AID and attenuates SCF expression in cultured granulosa cells

We next sought to determine how AID expression is regulated in the cross-talk between oocytes and granulosa cells. Since GDF-9 was reportedly a pivotal secretory factor ${ }^{24,25}$, we cultivated primary granulosa cells from 3-week old wild-type mice. In the absence of GDF-9, there was a rapid and marked decrease in AID expression during a 6-hour culture (Fig. 5A). In contrast, in the presence of GDF-9, AID expression was completely maintained (Fig. 5A). Another oocyte-derived factor, bone morphogenetic protein-15 (BMP-15), also showed enhancing effects on AID expression, but it recovered only a small part of the lost AID expression (Fig. 5A).

On the other hand, the mRNA expression of SCF was more than 3-times increased during a 6-hour culture (Fig. 5B). This increase was completely suppressed by GDF-9, as previously reported ${ }^{26}$. In contrast, BMP-15 showed no effects on SCF expression in cultured granulosa cells (Fig. 5B).

\section{AID attenuates SCF expression in cultured granulosa cells}

To further verify whether intrinsic AID is responsible for SCF expression in 
1 granulosa cells, we performed an RNA interference assay. We cultured granulosa cells in the

2 presence of GDF-9, where AID expression was maintained and SCF expression was not

3 increased under the influence of GDF-9. When we performed knockdown of AID mRNA,

4 both siRNA-AID_1 and siRNA-AID_2 significantly suppressed the mRNA expression of AID

5 (Fig. 5C). Under this condition, SCF expression was significantly suppressed (Fig. 5D), which

6 is consistent with the altered gene expression observed in AID-KO mice (Fig. 3). The results

7 suggest that AID expression in granulosa cells was responsible for SCF expression.

8

\section{AID did not change DNA methylation profiles of SCF and GDF-9}

AID has been suggested to be involved in epigenetic regulation through DNA methylation ${ }^{9,27}$. Consequently, we examined the DNA methylation profiles of SCF and GDF9 using cultured granulosa cells and ovarian tissues. In the granulosa cell culture, geneknockdown of AID did not change methylation profiles of SCF and GDF-9 (Fig. 6A and B). We also observed no differences in methylation profiles of SCF and GDF-9 in the ovarian tissues between wild-type and AID-KO mice (Fig. 6C and D).

\section{Discussion}

This study is the first report demonstrating that AID positively regulates folliculogenesis-related factors, including SCF. GDF-9 is an oocyte-secreted soluble factor, and was shown to maintain AID expression in granulosa cells. In turn, AID is necessary for SCF expression, important for the growth and survival of oocytes. Our findings suggest that AID is involved in cross-talk between oocytes and granulosa cells during folliculogenesis.

GDF-9 is a member of the transforming growth factor-beta (TGF- $\beta$ ) superfamily and was reported to be specifically expressed in oocytes ${ }^{28}$. GDF-9 is considered to control the rate-limiting step in the early development of follicles. GDF-9-KO mice showed decrease 
1 in proliferation of granulosa cells and arrest of follicle development in the primary stage,

2 leading to failed ovulation and no pregnancies ${ }^{24,25}$. On the other hand, SCF is a ligand for C-

3 kit that is expressed on oocytes and theca cells in murine follicles. SCF was proposed to

4 regulate the growth of oocytes ${ }^{29,30}$ and theca cells ${ }^{31}$. It was reported that murine oocytes

5 developed two-fold in the presence of SCF on in vitro culture, which corresponds to the early

6 stages of oocyte growth ${ }^{29}$. In addition, inhibition of the SCF/c-kit interaction by anti-c-kit

7 antibody induced oocyte death on in vitro culture ${ }^{30}$. SCF was also demonstrated to prevent

8 oocytes in the primordial follicles from undergoing apoptosis in ovarian organ culture ${ }^{32}$.

9 Furthermore, GDF-9 reportedly suppresses SCF expression ${ }^{33,34}$, whereas SCF interacts with

10 oocytes and increases GDF-9 expression as negative feedback ${ }^{33}$. In the GDF-9-KO mouse,

11 SCF expression was increased as high as 32 times, showing the continuous growth of oocytes

$12{ }^{25}$. The above previous reports collectively indicate that GDF-9 and SCF contribute to critical

13 cross-talk between oocytes and granulosa cells during oocyte development and follicular 14 growth.

From the expression profiles of GDF-9 and SCF in AID-KO mice, we suggest that

16 AID enhances GDF-9 and SCF expression in follicles. To investigate this possibility, we 17 employed a primary culture of granulosa cells. In this culture system, we confirmed the 18 suppressive effects of GDF-9 on SCF expression, as previously reported ${ }^{33,34}$ (Fig. 5B). Then, 19 we examined the effects of gene suppression of AID by siRNA on SCF expression. This down20 regulation of AID deduced SCF expression, supporting the above suggestion that AID 21 enhances SCF expression. This also suggests that AID is involved in critical cross-talk 22 between oocytes and granulosa cells through the GDF-9 and SCF feedback system. Since AID is not a growth factor, the direct mechanism of the decreased expression 24 of SCF in AID-KO mice and AID-knockdown granulosa cells is unknown. To explain this 25 mechanism, we focused on the roles of AID in epigenetic regulation of DNA demethylation. 
1 AID reportedly induces demethylation by deaminating 5-methylcytosine to thymine, followed

2 by base excision repair replacing thymine with non-methylated cytosine ${ }^{9,27}$. Nonetheless, AID

3 knockdown did not affect methylation of SCF or GDF-9 (Fig. 6). The mechanism by which

4 AID positively regulates the expression of folliculogenesis-related genes remains to be

5 elucidated. An intriguing possibility, which yet remains to be verified, is that AID binds to and

6 stabilizes the target mRNAs. APOBEC1 reportedly binds to the 3' UTRs of mRNA and

7 increases its stability ${ }^{35,36}$. In murine enterocytes, APOBEC1 was reported to bind to

8 cyclooxygenase 2 mRNA, increasing its expression and prostaglandin E2 synthesis ${ }^{36}$.

9 Consequently, AID may contribute to the stabilization of SCF mRNA, but this requires further 10 study.

11 This study showed that AID expression was rapidly diminished in the absence of

12 GDF-9 (Fig. 5A), suggesting that continuous stimulation of GDF-9 is necessary to maintain

13 AID expression in granulosa cells. Since GDF-9 is a member of the TGF- $\beta$ superfamily, the

14 regulation of AID expression in granulosa cells by GDF-9 is compatible with our previous

15 findings that AID expression is induced by TGF- $\beta$ in a murine B-cell lymphoma line ${ }^{37}$. GDF-

16 9-induced AID may counteract the suppressive action of GDF-9 on SCF production. Since

17 granulosa cells in the antral follicles have follicular fluid, a liquid environment, the

18 concentrations of GDF-9 and SCF in the follicular cavity are relatively stable. However, in

19 smaller follicles without follicular fluid, the change in GDF-9 production by oocytes rapidly

20 influence SCF production by adjacent granulosa cells. AID may be important to modulate the

21 GDF-9 and SCF feedback system as a buffering role.

Although we detected mRNA and protein of AID in oocytes by RT-PCR and

23 immunohistological staining (Fig. 1), RFP expression was not observed in oocytes of AID-

24 Cre/Rosa-tdRFP reporter mice (Fig. 2). This might be simply attributed to its lower expression

25 level in oocytes, unable to drive detectable tdRFP expression via Cre recombinase. 
1 Alternatively, AID mRNA in oocytes might have an exogenous origin. Since AID is a

2 candidate to control epigenetic reprogramming ${ }^{6,17,18}$, the presence of AID in oocytes is an

3 important issue from the perspective of genetic regulation. Indeed, follicular EVs were

4 reported to contain granulosa cell-derived $\mathrm{mRNA}^{11}$, and it is intriguing to consider that mRNA

5 of AID is transported from granulosa cells through follicular EVs ${ }^{12-15}$. In addition, a recent

6 study demonstrated that murine oocytes were directly connected to granulosa cells, by fusing

7 their cellular membrane, which enables the transport of large molecules including GDF-9,

8 from oocytes to granulosa cells ${ }^{38}$. This connection may transport AID protein from granulosa

9 cells to oocytes. The exact origin of AID in oocytes remains to be determined.

This study had several limitations. First, although AID was shown to regulate

11 folliculogenesis-related genes including GDF-9 and SCF, we could not find evidence that AID

12 ablation affected fertility under physiological conditions (Fig. 4). This suggests that the

13 reduction of GDF9 and SCF axis is compensated for by another system. However, we could

14 not detect these candidates from the microarray data. Second, the mechanism of AID-induced

15 changes in gene expression of SCF in granulosa cells and GDF-9 in oocytes remains unclear.

16 The possible involvement of epigenetic changes in this mechanism should be further

17 investigated. Third, the phenotype of the ovarian function in the aged AID-KO mouse was not

18 investigated. Since insufficient GDF-9 may promote follicle atresia ${ }^{39}$, additional investigation

19 of the effect of AID deficiency on fertility in the state of aging or under stress conditions

20 should be performed. Finally, the direct effects of AID on oocyte function should be clarified.

21 In conclusion, this study demonstrated the role of AID in regulating gene expression

22 of follicular cells, suggesting its possible involvement in regulating cross-talk between

23 oocytes and granulosa cells. Further studies are warranted to clarify its precise role in

24 folliculogenesis. 
Methods

2

\section{Mice}

C57BL/6 mice at the indicated ages and gestational stages were purchased from Japan Sankyo Lab Service Corporation. AID-KO mice were crossed with C57BL/6 mice for more than 10 generations ${ }^{2}$. The Aicda-cre/Rosa-tdRFP mouse ${ }^{7}$ was prepared by mating Aicda-cre ${ }^{40}$ and Rosa-tdRFP ${ }^{41}$ mice, which were backcrossed at least 10 times on a C57BL/6 background. This mouse showed the transcriptional history of Aicda mRNA as the intracellular expression of RFP (red fluorescent protein). The mice were bred under specific pathogen-free conditions with a natural day/night cycle, fed freely with food and water, and handled in accordance with the guidelines for animal experiments of Kanazawa University.

\section{Immunostaining methods}

The small intestines and ovaries of mice were fixed for 2 hours at $4^{\circ} \mathrm{C}$ in a fresh solution of $4 \%$ paraformaldehyde (Wako, Japan). The samples were then washed in PBS, incubated overnight at $4{ }^{\circ} \mathrm{C}$ in a solution of $30 \%$ sucrose, and embedded in OCT compound (Sakura Finetek). The tissue segments were sectioned with a cryostat at $8 \mu \mathrm{m}$ and stained for AID using a tyramide signal amplification system kit with TSA Plus TMR (PerkinElmer) ${ }^{42}$. GDF-9 were assessed by indirect immunofluorescent staining. Immunohistochemical staining was performed using a standard avidin-biotin complex peroxidase method, as described previously ${ }^{43}$. The primary antibodies used in this study were as follows: rat monoclonal antiAID antibody MAID-2 (eBioscience, 14-5959-80) ${ }^{44}$, rat monoclonal anti-AID antibody (Merck Millipore MABF63, clone 328.8), rabbit polyclonal anti-GDF9 antibody (abcam, ab93862), and rat IgG2b kappa isotype control (eBioscience, 16-4031-81, clone eB149/10H5).

The secondary antibodies used in this study were as follows: Peroxidase AffiniPure F(ab') 2 donkey anti-rat IgG antibody (H+L) (Jackson Immunoresearch, 712-036-153), Cy3conjugated goat anti-rabbit IgG antibody (Chemicon, AP132C). 


\section{Follicle count}

The number of follicles was counted in three different cross-sections in six ovaries of three mice. A secondary follicle was defined by two or more layers of granulosa cells, and an early antral follicle was defined by two or more layers of granulosa cells with a small antral cavity. Only follicles containing an oocyte were counted. Follicle counts were reported as the average number of follicles per ovarian surface area $\left(\mathrm{mm}^{2}\right)$. The differences in follicle counts were analyzed by the Mann-Whitney U test.

\section{Isolation of oocytes and granulosa cells}

Non-stimulated ovaries from 3-week-old female mice were prepared. We punctured ovaries in the DMEM/F12 culture medium with a 28-gauge needle under a stereomicroscope, and follicles, oocytes, and granulosa cells were released. Oocytes without granulosa cells were isolated manually by a glass micropapillary tube tapered with a burner. If a small number of granulosa cells were attached, they were removed by suction and flushing. Granulosa cells were separated from oocytes and follicles by filtering the suspension through a nylon mesh (40 $\mu \mathrm{m}$; BD Falcon, Bedford, MA, USA), which allowed granulosa cells but not oocytes or follicles to pass through ${ }^{45}$.

\section{Culture of granulosa cells}

Non-stimulated ovarian follicles from 3-week-old female mice were punctured with a 28-gauge needle, and a mixture of granulosa cells and oocytes was isolated. Granulosa cells were separated from oocytes by filtering the suspension through a $40 \mu \mathrm{m}$ nylon mesh. The granulosa cells were cultured at $37{ }^{\circ} \mathrm{C}$ in a humidified atmosphere $(5 \% \mathrm{CO} 2$ and $95 \%$ air) in DMEM/F12 supplemented with $0.5 \%$ heat-inactivated Fetal Bovine Serum, $5 \mu \mathrm{g} / \mathrm{mL}$ of insulin, $5 \mu \mathrm{g} / \mathrm{mL}$ of transferrin, $5 \mathrm{ng} / \mathrm{mL}$ of sodium selenite, and $1 \%$ penicillin-streptomycin. Granulosa cells were treated for 6 hours with medium containing the solvent or $300 \mathrm{ng} / \mathrm{mL}$ of 
1 recombinant mouse GDF-9 (739-G9, R\&D Systems) or recombinant human BMP-15 (5096-

2 BM, R\&D Systems).

3

$R T-q P C R$

Total RNA of the mouse ovary was extracted using TRIsure reagent (Bioline, UK).

6 Total RNA from mouse follicles, granulosa cells, and oocytes was extracted using an

7 RNeasy micro kit (Qiagen). Extracted total RNA was treated with amplification-grade

8 DNase I (Invitrogen) and reverse-transcribed using Prime Script reverse transcriptase

9 (Takara Bio Inc., Shiga, Japan) with random primers (nonadeoxyribonucleotide mixture;

$\left.10 \operatorname{pd}(\mathrm{N})_{9}\right)$ and oligo dT primers (Takara Bio Inc.). The cDNA was amplified using specific

11 primers (Table 1). Quantitative PCR analysis was performed using SYBR Premix Ex Taq

12 (Takara) on an MX3000 thermo-cycler (Stratagene) following the PCR protocol: a single

13 hot-start cycle at $95^{\circ} \mathrm{C}$ for $30 \mathrm{sec}$, followed by 36 cycles of denaturing at $95^{\circ} \mathrm{C}$ for $5 \mathrm{sec}$,

14 annealing, and extension at $60^{\circ} \mathrm{C}$ for $20 \mathrm{sec}$. Amplification was completed by an additional

15 cycle at $95^{\circ} \mathrm{C}$ for $1 \mathrm{~min}$, and PCR products were analyzed by $4 \%$ agarose gel electrophoresis

16 and stained with ethidium bromide. Relative gene expression was analyzed using the 2-

$17 \Delta \Delta \mathrm{CT}$ method. Results are expressed as the means +/- SD of at least two separate experiments

18 using two or more mice. Differences between groups were analyzed for significance by

19 ANOVA or unpaired $t$-tests. $P$-values $<0.05$ were accepted as significant.

\section{Microarray analysis}

Total RNA from mouse granulosa cells was extracted for microarray analysis. Using 3-week-old female wild-type and AID-KO mice, follicles were punctured with a 28-gauge needle and granulosa cells were separated from oocytes by filtering the suspension through a 40- $\mu \mathrm{m}$ nylon mesh. Microarray experiments were performed using SurePrint G3 Mouse 
$18 \times 60 \mathrm{~K}$ ver. 2.0. Data analysis was performed using GeneSpring GX software (Agilent

2 Technologies). In brief, raw intensity data were calculated with Agilent Feature Extraction

$3 \quad 12.0 .3 .1$ and normalized as a 75 percentile shift according to the protocol.

Differential Expressed Genes were extracted from normalized microarray intensity data using the weighted average difference (WAD) ranking method ${ }^{46}$. This method is a statistical approach based on the fold-change method that uses not only the difference in gene expression, but also the signal intensity in microarrays. Fold-change was calculated by dividing the AID-KO value by the wild-type value.

\section{RNA interference assay}

AID-siRNA (MSS235859-60, Thermo Fisher Scientific) and negative control siRNA (AM4635, Ambion) were used. siRNA transfections were carried out by the reverse transfection method with Lipofectamine RNAi MAX according to the manufacturer's instructions. In brief, 20 pmol siRNA and $1 \mu \mathrm{L}$ of Lipofectamine RNAi MAX were incubated in $100 \mu \mathrm{L}$ Opti-MEM medium (Thermo Fisher Scientific) for $20 \mathrm{~min}$ at room temperature in 24-well plates, and then $500 \mu \mathrm{L}$ of cell suspension $\left(2.0 \times 10^{5}\right.$ cells $)$ was added to the siRNARNAi MAX complex. The cells were incubated for $48 \mathrm{~h}$ at $37{ }^{\circ} \mathrm{C}$ in a humidified atmosphere containing 5\% CO2 and 95\% air in the DMEM/F12 described above with $1000 \mathrm{ng} / \mathrm{mL}$ of recombinant mouse GDF-9.

\section{DNA methylation assay}

DNA from individual mouse ovaries and granulosa cells was extracted and bisulfite converted using the EZ DNA Methylation Gold Kit (Zymo Research, Orange, CA USA) according to the manufacturer's instructions and was eluted in $20 \mu \mathrm{L}$ of water. Pyrosequencing primers were designed for each target of interest using PyroMark Assay Design 2.0 software

26 (Qiagen Inc., CA, USA) to amplify the bisulfite-modified target region. PCR reactions were 
1 carried out with 25 ng of bisulfite-converted DNA using the PyroMark PCR kit (Qiagen Inc.,

$2 \mathrm{CA}$ ) in a final volume of $25 \mu \mathrm{L}$ containing $12.5 \mu \mathrm{L}$ 1x PyroMark PCR Master Mix, $2.5 \mu \mathrm{L} 1 \mathrm{x}$

3 CoralLoad Concentrate, $0.5 \mu \mathrm{L}$ of each primer in a final concentration of $0.05 \mu \mathrm{M}$, and $8 \mu \mathrm{L}$

4 of water. Amplification conditions were as follows: $95^{\circ} \mathrm{C}$ for $15 \mathrm{~min}, 45$ cycles of $94{ }^{\circ} \mathrm{C}$ for

$530 \mathrm{~s}, 56^{\circ} \mathrm{C}$ for $30 \mathrm{~s}$, and $72{ }^{\circ} \mathrm{C}$ for $30 \mathrm{~s}$, and finally, $72{ }^{\circ} \mathrm{C}$ for $10 \mathrm{~min}$. The pyrosequencing

6 was performed using a Pyromark Q24 pyrosequencer (Qiagen Inc., CA) following the

7 manufacturer's recommended protocols. Pyromark Q24 software was used to calculate the

8 percent methylation for each $\mathrm{CpG}$ site. The results are displayed as a pyrogram with the

9 methylation percentage.

11 Acknowledgement

We thank Ms. Ai Sato and Ms. Mai Kawakita (Kanazawa University) for their 13 technical support. We thank Dr. Maki Kobayashi and Dr. Kazuo Kinoshita for providing the 14 mice ovary samples. This work was supported in part by Grants-in-Aid for Scientific Research 15 (nos. 18K16792, 19K22681, 26293358, 26293103).

16

\section{Author Contributions}

T.I. and T.S. performed the experiments. T.I., K.W., H.F., and M.M. designed the study. T.I., K.W., and H.F. wrote the manuscript. T.I., K.K., M.O., K.W., H.F., and M.M. 20 discussed the results. 


\section{References}

1 Harris, R. S. \& Liddament, M. T. Retroviral restriction by APOBEC proteins. Nat Rev Immunol 4, 868-877, doi:10.1038/nri1489 (2004).

2 Muramatsu, M. et al. Class switch recombination and hypermutation require activation-induced cytidine deaminase (AID), a potential RNA editing enzyme. Cell 102, 553-563, doi:10.1016/s0092-8674(00)00078-7 (2000).

Sapoznik, S. et al. Activation-Induced Cytidine Deaminase Links Ovulation-Induced Inflammation and Serous Carcinogenesis. Neoplasia 18, 90-99, doi:10.1016/j.neo.2015.12.003 (2016).

4 Matsumoto, Y. et al. Helicobacter pylori infection triggers aberrant expression of activation-induced cytidine deaminase in gastric epithelium. Nat Med 13, 470-476, doi:10.1038/nm1566 (2007).

5 Nonaka, T. et al. Involvement of activation-induced cytidine deaminase in skin cancer development. J Clin Invest 126, 1367-1382, doi:10.1172/JCI81522 (2016).

6 Morgan, H. D., Dean, W., Coker, H. A., Reik, W. \& Petersen-Mahrt, S. K. Activationinduced cytidine deaminase deaminates 5-methylcytosine in DNA and is expressed in pluripotent tissues: implications for epigenetic reprogramming. $J$ Biol Chem 279, 52353-52360, doi:10.1074/jbc.M407695200 (2004).

7 Qin, H. et al. Activation-induced cytidine deaminase expression in CD4+ T cells is associated with a unique IL-10-producing subset that increases with age. PLoS One 6, e29141, doi:10.1371/journal.pone.0029141 (2011).

8 Cortesao, C. S., Freitas, R. F. \& Barreto, V. M. Activation-Induced Cytidine Deaminase Does Not Impact Murine Meiotic Recombination. G3 (Bethesda) 3, 645-655, doi:10.1534/g3.113.005553 (2013).

9 Popp, C. et al. Genome-wide erasure of DNA methylation in mouse primordial germ cells is affected by AID deficiency. Nature 463, 1101-1105, doi:10.1038/nature08829 (2010).

10 Pauklin, S., Sernandez, I. V., Bachmann, G., Ramiro, A. R. \& Petersen-Mahrt, S. K. 
Estrogen directly activates AID transcription and function. $J$ Exp Med 206, 99-111, doi:10.1084/jem.20080521 (2009).

11 Matsuno, Y. et al. Characterization of mRNA profiles of the exosome-like vesicles in porcine follicular fluid. PLoS One 14, e0217760, doi:10.1371/journal.pone.0217760 (2019).

Grzesiak, M., Popiolek, K. \& Knapczyk-Stwora, K. Extracellular vesicles in follicular fluid of sexually mature gilts' ovarian antral follicles - identification and proteomic analysis. J Physiol Pharmacol 71, doi:10.26402/jpp.2020.1.13 (2020).

Di Pietro, C. Exosome-mediated communication in the ovarian follicle. J Assist Reprod Genet 33, 303-311, doi:10.1007/s10815-016-0657-9 (2016).

1114 Matsuno, Y. et al. Effects of exosome-like vesicles on cumulus expansion in pigs in vitro. J Reprod Dev 63, 51-58, doi:10.1262/jrd.2016-124 (2017). gamete maturation, fertilization and embryo implantation. Hum Reprod Update 22,

17 Teperek-Tkacz, M., Pasque, V., Gentsch, G. \& Ferguson-Smith, A. C. Epigenetic reprogramming: is deamination key to active DNA demethylation? Reproduction 142, 621-632, doi:10.1530/REP-11-0148 (2011).

18 Nabel, C. S. et al. AID/APOBEC deaminases disfavor modified cytosines implicated 2419 Muramatsu, M. et al. Specific expression of activation-induced cytidine deaminase (AID), a novel member of the RNA-editing deaminase family in germinal center B cells. J Biol Chem 274, 18470-18476, doi:10.1074/jbc.274.26.18470 (1999).

Qin, H. et al. Activation-induced cytidine deaminase expression in CD4+ T cells is associated with a unique IL-10-producing subset that increases with age. PLoS One 6, 
e29141, doi:10.1371/journal.pone.0029141 (2011).

21 Wang, J. \& Roy, S. K. Growth differentiation factor-9 and stem cell factor promote primordial follicle formation in the hamster: modulation by follicle-stimulating hormone. Biol Reprod 70, 577-585, doi:10.1095/biolreprod.103.023234 (2004).

22 Guo, C. et al. Interaction of Follicle-Stimulating Hormone and Stem Cell Factor to Promote Primordial Follicle Assembly in the Chicken. Front Endocrinol (Lausanne) 10, 91, doi:10.3389/fendo.2019.00091 (2019).

23 Dong, J. et al. Growth differentiation factor-9 is required during early ovarian folliculogenesis. Nature 383, 531-535, doi:10.1038/383531a0 (1996).

24 Hennet, M. L. \& Combelles, C. M. The antral follicle: a microenvironment for oocyte differentiation. Int J Dev Biol 56, 819-831, doi:10.1387/ijdb.120133cc (2012).

25 Elvin, J. A., Yan, C., Wang, P., Nishimori, K. \& Matzuk, M. M. Molecular characterization of the follicle defects in the growth differentiation factor 9-deficient ovary. Mol Endocrinol 13, 1018-1034, doi:10.1210/mend.13.6.0309 (1999).

26 Thomas, F. H., Ethier, J. F., Shimasaki, S. \& Vanderhyden, B. C. Follicle-stimulating hormone regulates oocyte growth by modulation of expression of oocyte and granulosa cell factors. Endocrinology 146, 941-949, doi:10.1210/en.2004-0826 (2005).

27 Rai, K. et al. DNA demethylation in zebrafish involves the coupling of a deaminase, a glycosylase, and gadd45. Cell 135, 1201-1212, doi:10.1016/j.cell.2008.11.042 (2008). 28 Knight, P. G. \& Glister, C. TGF-beta superfamily members and ovarian follicle development. Reproduction 132, 191-206, doi:10.1530/rep.1.01074 (2006).

29 Klinger, F. G. \& De Felici, M. In vitro development of growing oocytes from fetal mouse oocytes: stage-specific regulation by stem cell factor and granulosa cells. Dev Biol 244, 85-95, doi:10.1006/dbio.2002.0592 (2002).

30 Reynaud, K., Cortvrindt, R., Smitz, J. \& Driancourt, M. A. Effects of Kit Ligand and anti-Kit antibody on growth of cultured mouse preantral follicles. Mol Reprod Dev 56, 483-494, doi:10.1002/1098-2795(200008)56:4<483::AID-MRD6>3.0.CO;2-O (2000).

31 Parrott, J. A. \& Skinner, M. K. Direct actions of kit-ligand on theca cell growth and 
1 differentiation during follicle development. Endocrinology 138, 3819-3827, doi:10.1210/endo.138.9.5368 (1997).

332 Jin, X. et al. Anti-apoptotic action of stem cell factor on oocytes in primordial follicles $4 \quad$ and its signal transduction. Mol Reprod Dev 70, 82-90, doi:10.1002/mrd.20142 (2005).

533 Miyoshi, T. et al. Regulatory role of kit ligand-c-kit interaction and oocyte factors in 6 steroidogenesis by rat granulosa cells. Mol Cell Endocrinol 358, 18-26, doi:10.1016/j.mce.2012.02.011 (2012).

834 Joyce, I. M., Clark, A. T., Pendola, F. L. \& Eppig, J. J. Comparison of recombinant growth differentiation factor-9 and oocyte regulation of KIT ligand messenger ribonucleic acid expression in mouse ovarian follicles. Biol Reprod 63, 1669-1675, doi:10.1095/biolreprod63.6.1669 (2000).

1235 Blanc, V. et al. Deletion of the AU-rich RNA binding protein Apobec-1 reduces 13 intestinal tumor burden in Apc(min) mice. Cancer Res 67, 8565-8573, doi:10.1158/0008-5472.CAN-07-1593 (2007).

36 Anant, S. et al. Apobec-1 protects intestine from radiation injury through posttranscriptional regulation of cyclooxygenase-2 expression. Gastroenterology 127, 1139-1149, doi:10.1053/j.gastro.2004.06.022 (2004).

37 Muto, T., Muramatsu, M., Taniwaki, M., Kinoshita, K. \& Honjo, T. Isolation, tissue distribution, and chromosomal localization of the human activation-induced cytidine deaminase (AID) gene. Genomics 68, 85-88, doi:10.1006/geno.2000.6268 (2000).

2138 Komatsu, K. \& Masubuchi, S. Mouse oocytes connect with granulosa cells by fusing with cell membranes and form a large complex during follicle development. Biol Reprod 99, 527-535, doi:10.1093/biolre/ioy072 (2018).

2439 Orisaka, M. et al. Growth differentiation factor 9 is antiapoptotic during follicular development from preantral to early antral stage. Mol Endocrinol 20, 2456-2468, doi:10.1210/me.2005-0357 (2006).

40 Kwon, K. et al. Instructive role of the transcription factor E2A in early B lymphopoiesis and germinal center B cell development. Immunity 28, 751-762, 
doi:10.1016/j.immuni.2008.04.014 (2008).

241 Luche, H., Weber, O., Nageswara Rao, T., Blum, C. \& Fehling, H. J. Faithful activation of an extra-bright red fluorescent protein in "knock-in" Cre-reporter mice ideally suited for lineage tracing studies. Eur J Immunol 37, 43-53, doi:10.1002/eji.200636745 (2007).

42 Toda, Y. et al. Application of tyramide signal amplification system to immunohistochemistry: a potent method to localize antigens that are not detectable by ordinary method. Pathol Int 49, 479-483, doi:10.1046/j.1440-1827.1999.00875.x (1999).

43 Iizuka, T. et al. APOBEC3G is increasingly expressed on the human uterine cervical intraepithelial neoplasia along with disease progression. Am J Reprod Immunol 78,

1344 Tsuji, M. et al. Requirement for lymphoid tissue-inducer cells in isolated follicle formation and T cell-independent immunoglobulin A generation in the gut. Immunity 29, 261-271, doi:10.1016/j.immuni.2008.05.014 (2008).

45 Otsuka, F. \& Shimasaki, S. A negative feedback system between oocyte bone morphogenetic protein 15 and granulosa cell kit ligand: its role in regulating granulosa cell mitosis. Proc Natl Acad Sci U S A 99, 8060-8065, doi:10.1073/pnas.122066899 (2002). 8, doi:10.1186/1748-7188-3-8 (2008). 
1 Table 1. Primers for quantitative-PCR

2

3 Name Sequence $\left(5^{\prime}-3^{\prime}\right)$

Product size

4 Aicda Forward: CTGTGAAGACCGCAAGGCTGAG

5

Reverse: AATTTTCATGTAGCCCTTCCCAGG 161 bp

$6 \quad G d f 9$

Forward: CCTCTACAATACCGTCCGGC

7

Reverse: CACCCGGTCCAGGTTAAACA

$115 \mathrm{bp}$

8 Kitl (SCF) Forward: CATCCATCCCGGCGACATAG

9

Reverse: CATCCATCCCGGCGACATAG

$183 \mathrm{bp}$

10 Gapdh Forward: TGAAGCAGGCATCTGAGGG

11

Reverse: CGAAGGTGGAAGAGTGGGAG

102 bp

12 Gapdh: glyceraldehyde-3-phosphate dehydrogenase. Kitl: kit ligand. 


\section{Figure legends}

2 Figure 1. The expression profiles of AID protein in Peyer's patches and ovaries

3 A. Immunofluorescence of AID in 8-week-old mouse Peyer's patches and ovaries. The right

43 panels show magnified views of the white square areas outlined in the left panel. AID was

5 expressed in the germinal center of Peyer's patches. Of note, AID was expressed only in

6 follicles (arrows) and not expressed in the corpus luteum (arrowheads). Bars show $100 \mu \mathrm{m}$.

7 B. Immunohistochemical staining of AID in mouse follicles. Immunoreactive AID was

8 observed in granulosa cells and oocytes. C. AID staining of the ovaries using a different 9 antibody in wild-type and AID-KO mice. AID was also observed in granulosa cells and 10 oocytes (Oc), whereas no expression of AID was observed in the follicles of AID-KO mice.

11 Bars show $20 \mu \mathrm{m}$. D. RT-PCR analysis of AID and Gapdh mRNA expression. The mRNA 12 expression of AID in granulosa cells and oocytes was confirmed. The data shown are 13 representative of two independent experiments. E. Relative expression of AID in murine 14 oocytes, granulosa cells, and liver cells as a negative control. AID mRNA expression in 15 granulosa cells was higher than that in oocytes. Gapdh: glyceraldehyde-3-phosphate 16 dehydrogenase.

Figure 2. The transcriptional history of AID mRNA in the ovary

19 A. Immunofluorescence of the 8-week old mouse ovary of an Aicda-cre/Rosa-tdRFP mouse. 20 RFP (red) and DAPI (blue) signals are shown together. RFP was observed in both granulosa 21 cells in the cumulus (arrowhead) and mural (arrows) regions and lutein cells (LC) that are 22 derived from granulosa cells. Bars show $100 \mu \mathrm{m}$. B. A magnified view of the follicles. The 23 expression of RFP in oocytes was not detected (arrowhead). Bars show $20 \mu \mathrm{m}$. 
1 A. Gene ontology analysis of microarray study. Top 5 to 7 gene-ontology biological process

2 terms with threshold set at a P-value $<0.05$ from up- and down-regulated genes. B. RT-qPCR

3 showed the reduction of mRNA expression of GDF-9 and SCF in granulosa cells derived from

4 the AID-KO mouse. Gene expression of Gapdh was used as a control for qPCR analysis. C.

5 RT-qPCR showed that the mRNA expression of GDF-9 in oocytes was decreased in oocytes

6 derived from the AID-KO mouse. *, $\mathrm{P}<0.05 ; * *, \mathrm{P}<0.01$. D. Immunohistological

7 examination showed that the protein expression of GDF-9 was detected in oocytes and

8 granulosa cells in 3-week-old mouse ovaries, whereas its expression was reduced in the AID-

$9 \quad$ KO mouse. Bars show $100 \mu \mathrm{m}$.

11 Figure 4. Histological analysis of the follicles in AID-KO mice

12 A-B. Hematoxylin and eosin staining of paraffin-embedded formalin sections of 3-week-old 13 (A) and 8-week-old (B) wild-type and AID-KO mouse ovaries. In the ovaries of AID-KO mice, 14 there was no abnormality in the structure of the ovaries compared with the wild type. Bars 15 show $100 \mu \mathrm{m}$. C-D. The number of secondary follicles and antral follicles in 3-week (C) and 16 8-week (D) ovaries were calculated as the average number of follicles per ovarian surface area $17\left(\mathrm{~mm}^{2}\right)$. There was no significant difference in follicular numbers between wild-type and AID18 KO ovaries.

Figure 5. Regulation of SCF expression in cultured granulosa cells by GDF-9 and AID

21 A-D. Granulosa cells isolated from the 3-week ovary of wild-type mice were subjected to the 22 following culture experiments. AID and SCF expression relative to Gapdh in murine granulosa 23 cells assessed by qPCR. A. AID expression was markedly decreased during a 6-hour culture. 24 In contrast, AID expression was completely maintained in the presence of GDF-9. BMP-15 25 also showed enhancing effects on AID expression, but it recovered only a small part of the 
1 lost AID expression. B. The mRNA expression of SCF was more than 3-times increased during

2 a 6-hour culture. This increase was completely suppressed by GDF-9. BMP-15 showed no

3 effects on SCF expression in cultured granulosa cells. C. In the presence of GDF-9, both

4 siRNA-AID_1 and siRNA-AID_2 significantly suppressed the mRNA expression of AID

5 during a 48-hour culture. Under this condition, SCF expression was significantly reduced. *, $6 \quad \mathrm{P}<0.05 ; * *, \mathrm{P}<0.01$.

7

8 Figure 6. DNA methylation profiles of SCF and GDF-9

9 A-D. The DNA methylation profiles of SCF and GDF-9 using cultured granulosa cells (A and 10 B) and ovarian tissues (C and D). In the granulosa cell culture, there were no significant 11 differences in methylation profiles of SCF (A) and GDF-9 (B) among si-RNA-control, siRNA12 AID_1, and siRNA-AID_2 groups. There were also no differences in methylation profiles of 13 SCF (C) and GDF-9 (D) in the ovarian tissues between wild-type and AID-KO mice. 


\section{Figures}

Fig. 1
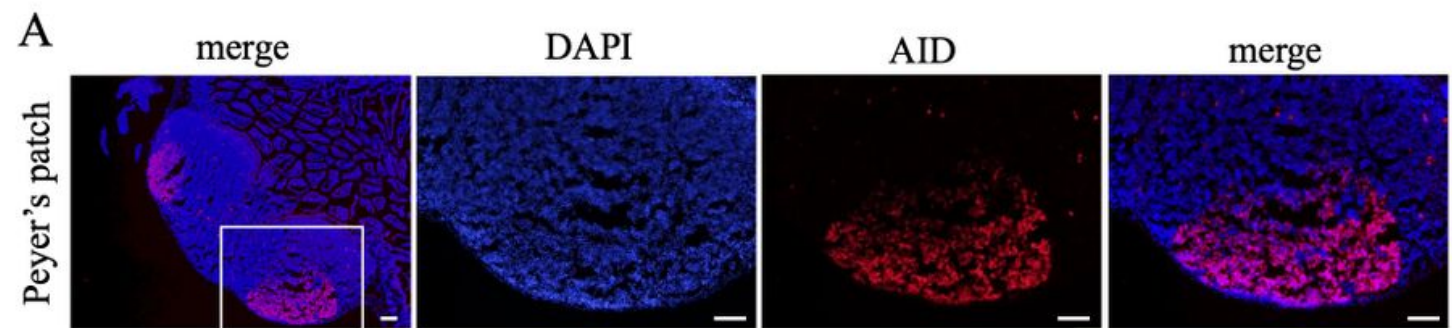

B
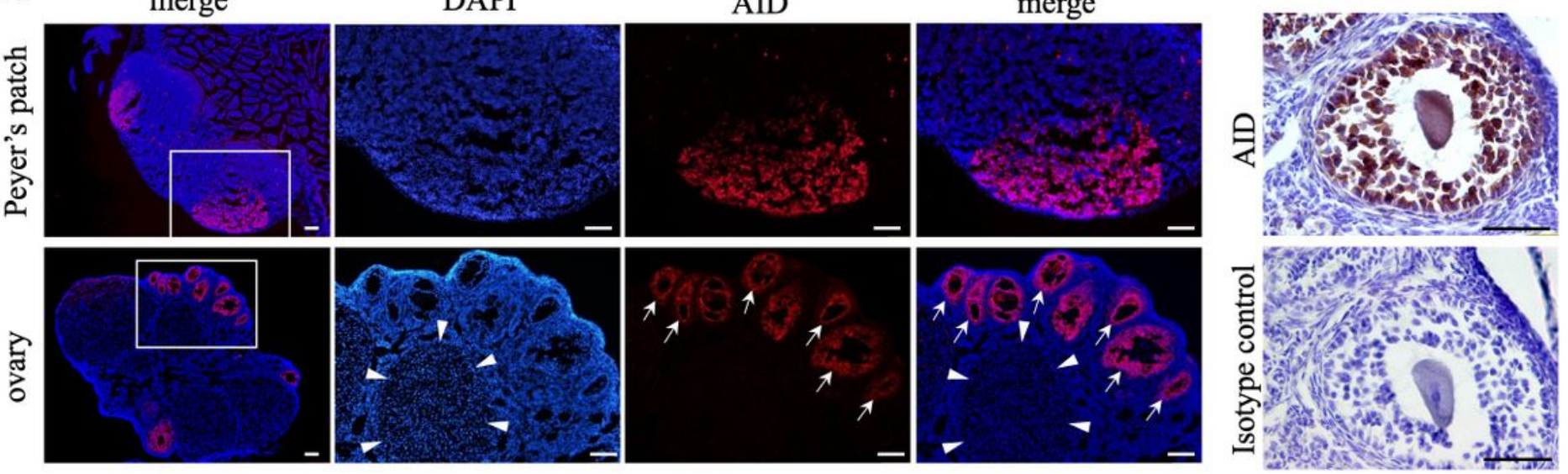

$\mathrm{C}$

merge

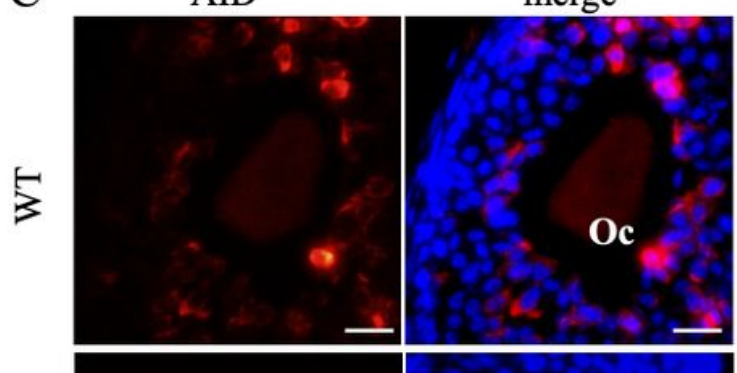

$\mathrm{D}$

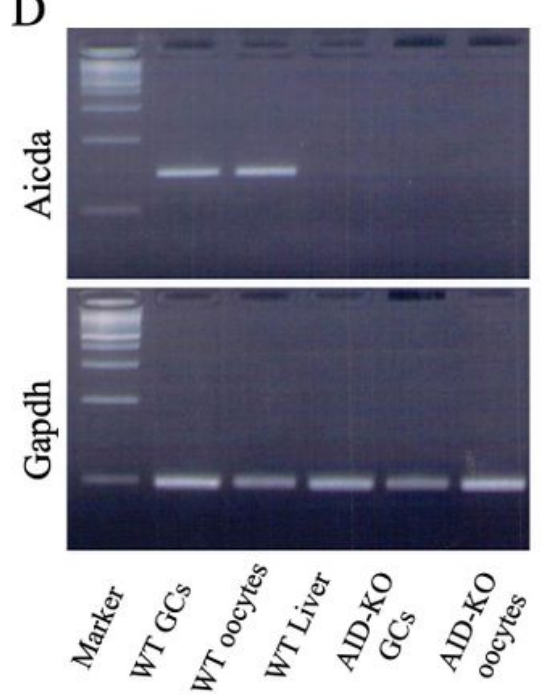

$\mathrm{E}$

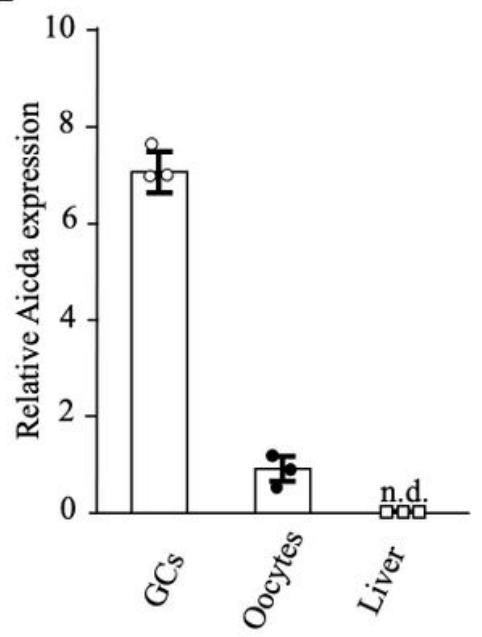

Figure 1

The expression profiles of AID protein in Peyer's patches and ovaries A. Immunofluorescence of AID in 8week-old mouse Peyer's patches and ovaries. The right 3 panels show magnified views of the white square areas outlined in the left panel. AID was expressed in the germinal center of Peyer's patches. Of note, AID was expressed only in follicles (arrows) and not expressed in the corpus luteum (arrowheads). Bars show $100 \mu \mathrm{m}$. B. Immunohistochemical staining of AID in mouse follicles. Immunoreactive AID was observed in granulosa cells and oocytes. C. AID staining of the ovaries using a different antibody in wildtype and AID-KO mice. AID was also observed in granulosa cells and oocytes (Oc), whereas no expression of AID was observed in the follicles of AID-KO mice. Bars show $20 \mu \mathrm{m}$. D. RT-PCR analysis of AID and Gapdh mRNA expression. The mRNA expression of AID in granulosa cells and oocytes was confirmed. The data shown are representative of two independent experiments. E. Relative expression of AID in murine oocytes, granulosa cells, and liver cells as a negative control. AID mRNA expression in granulosa cells was higher than that in oocytes. Gapdh: glyceraldehyde-3-phosphate dehydrogenase. 
Fig. 2
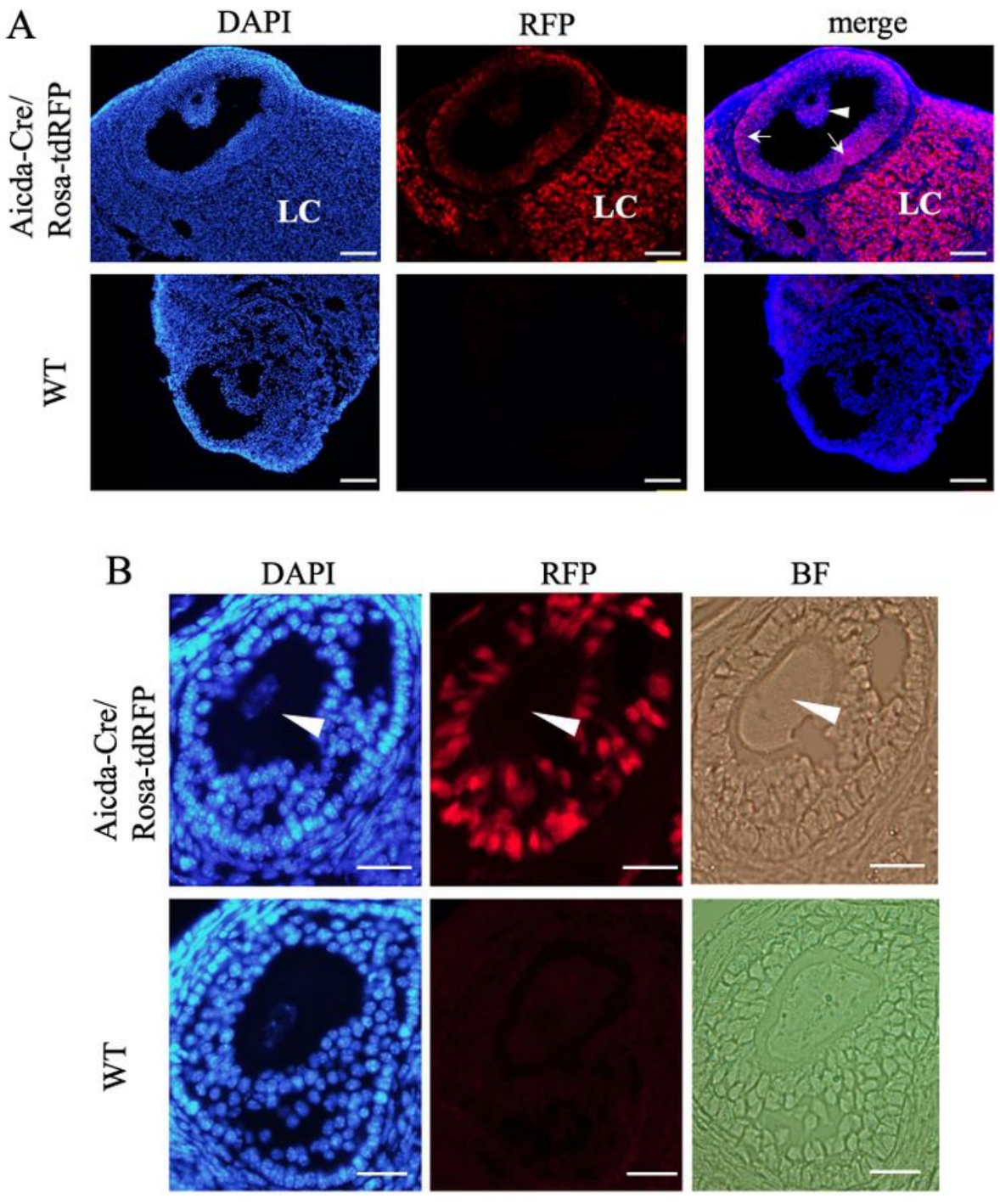

\section{Figure 2}

The transcriptional history of AID mRNA in the ovary A. Immunofluorescence of the 8-week old mouse ovary of an Aicda-cre/Rosa-tdRFP mouse. RFP (red) and DAPI (blue) signals are shown together. RFP was observed in both granulosa cells in the cumulus (arrowhead) and mural (arrows) regions and lutein cells (LC) that are derived from granulosa cells. Bars show $100 \mu \mathrm{m}$. B. A magnified view of the follicles. The expression of RFP in oocytes was not detected (arrowhead). Bars show $20 \mu \mathrm{m}$. 
Fig. 3

A
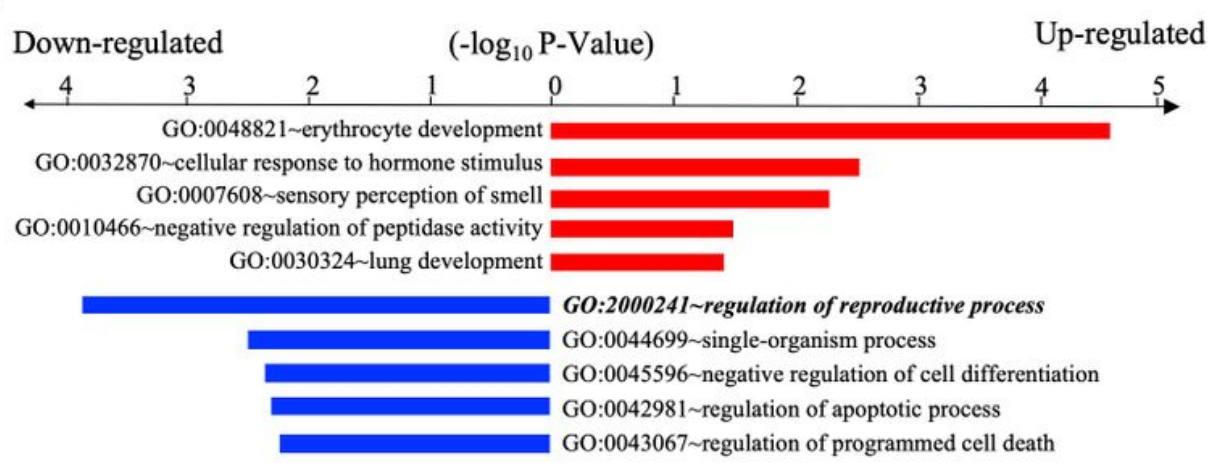

B

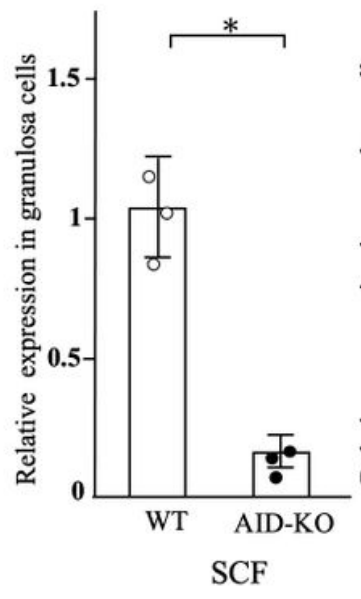

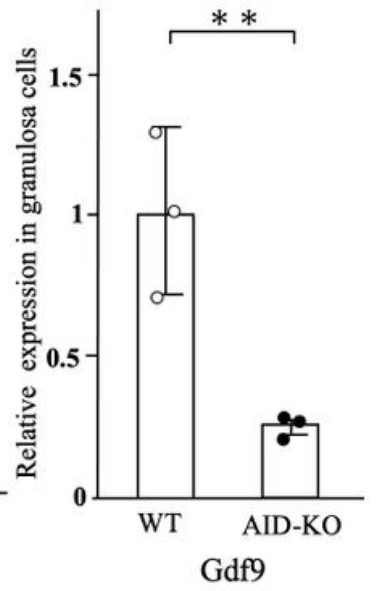

$\mathrm{C}$

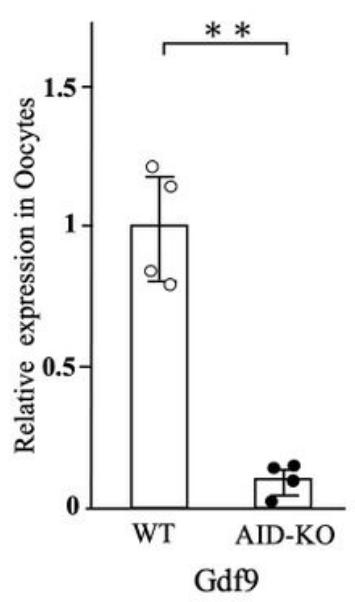

$\mathrm{D}$

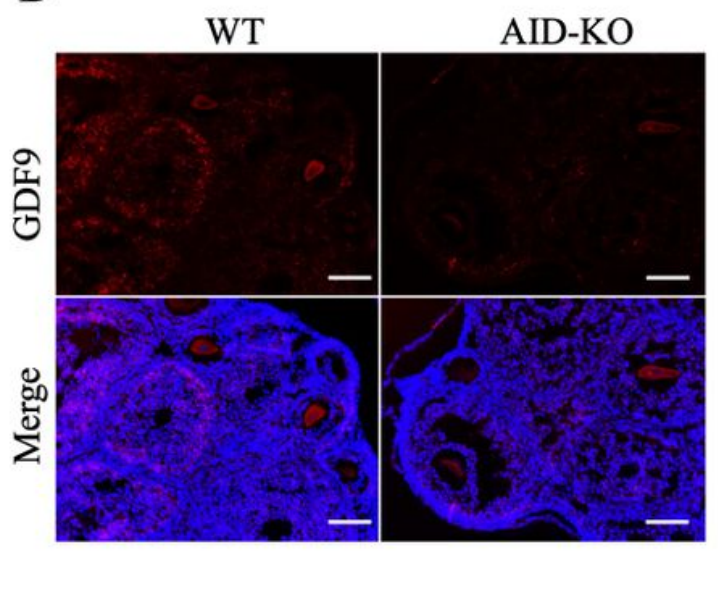

\section{Figure 3}

Analysis of GDF-9 and SCF expression in the follicles of AID-KO mice A. Gene ontology analysis of microarray study. Top 5 to 7 gene-ontology biological process terms with threshold set at a P-value $<0.05$ from up- and down-regulated genes. B. RT-qPCR showed the reduction of mRNA expression of GDF-9 and SCF in granulosa cells derived from the AID-KO mouse. Gene expression of Gapdh was used as a control for qPCR analysis. C. RT-qPCR showed that the mRNA expression of GDF-9 in oocytes was decreased in oocytes derived from the AID-KO mouse. ${ }^{*}, P<0.05$; $* \star, P<0.01$. D. Immunohistological examination showed that the protein expression of GDF-9 was detected in oocytes and granulosa cells in 3-week-old mouse ovaries, whereas its expression was reduced in the AID9 KO mouse. Bars show $100 \mu \mathrm{m}$. 
Fig. 4

A

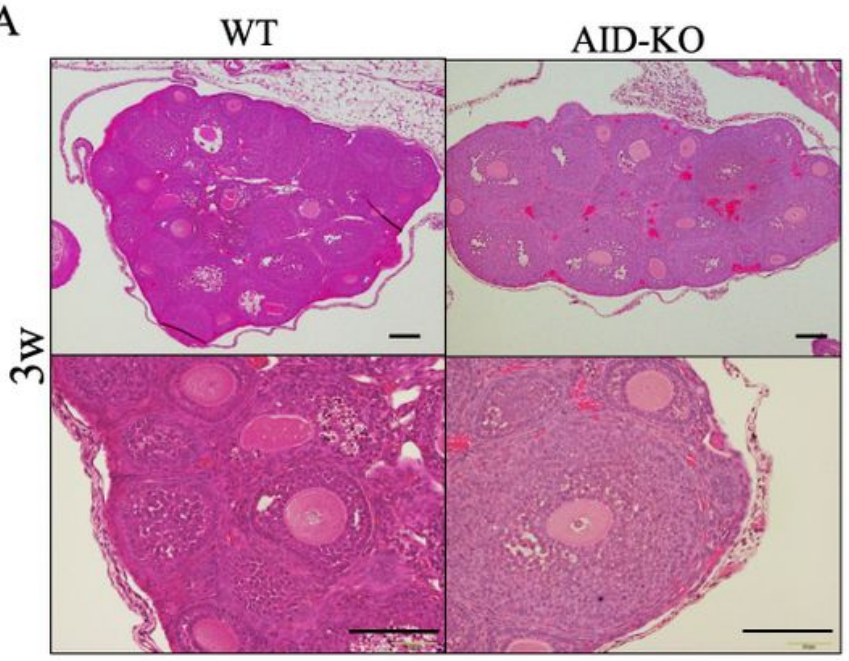

C

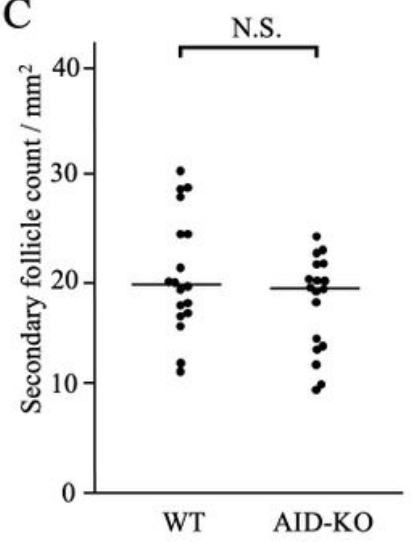

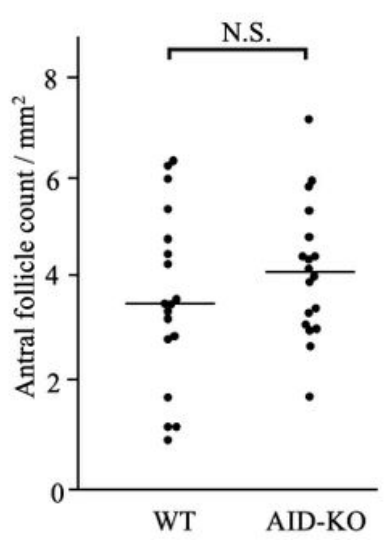

B
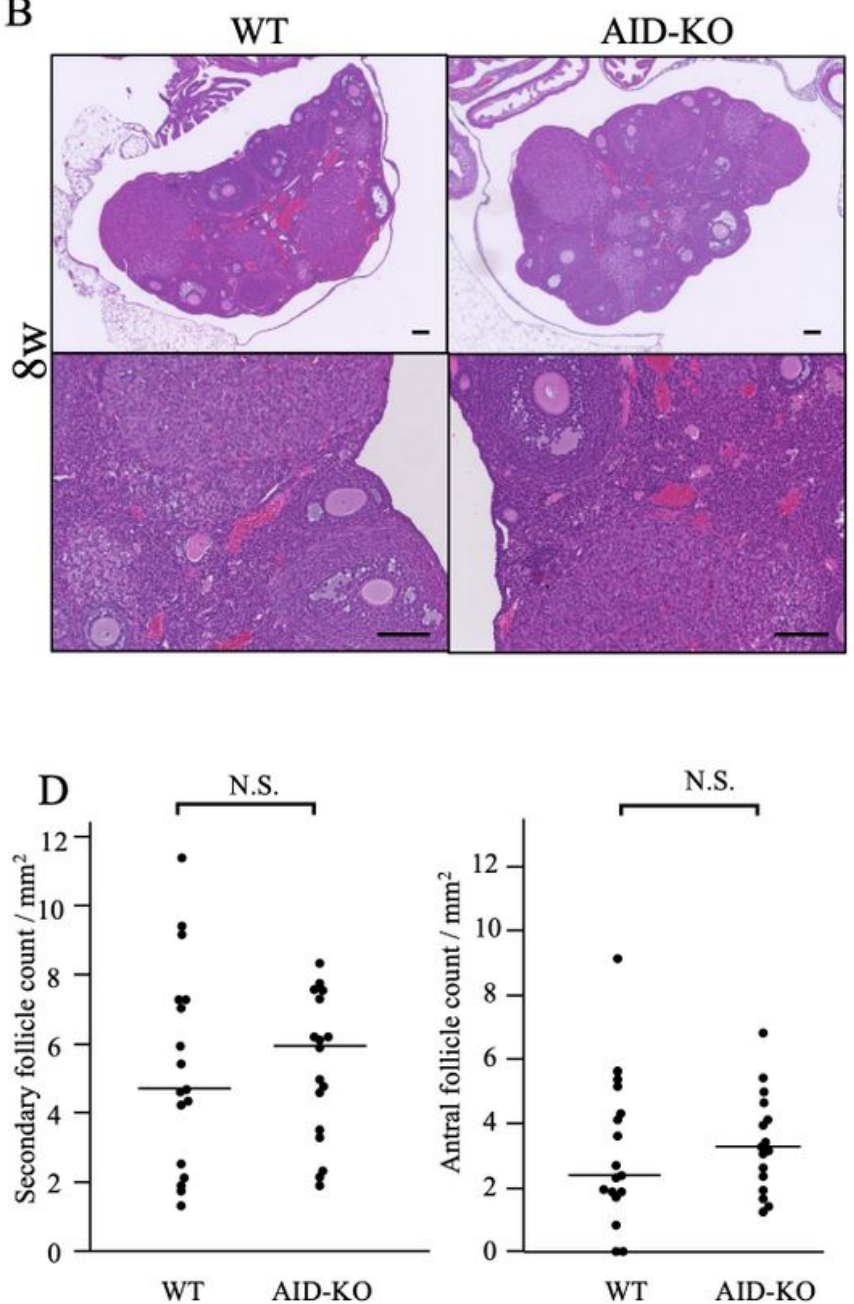

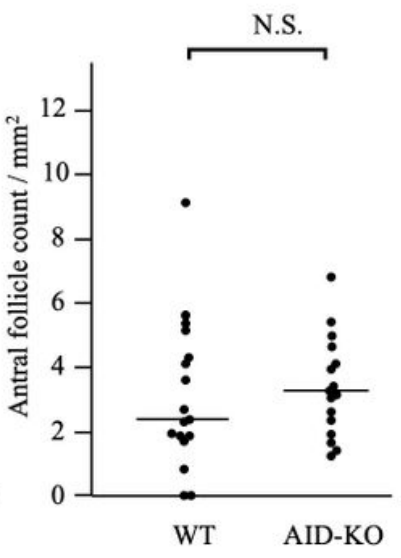

Figure 4

Histological analysis of the follicles in AID-KO mice A-B. Hematoxylin and eosin staining of paraffinembedded formalin sections of 3-week-old (A) and 8-week-old (B) wild-type and AID-KO mouse ovaries. In the ovaries of AID-KO mice, there was no abnormality in the structure of the ovaries compared with the wild type. Bars show $100 \mu \mathrm{m}$. C-D. The number of secondary follicles and antral follicles in 3-week (C) and 8-week (D) ovaries were calculated as the average number of follicles per ovarian surface area (mm2). There was no significant difference in follicular numbers between wild-type and AID18 KO ovaries. 
Fig. 5
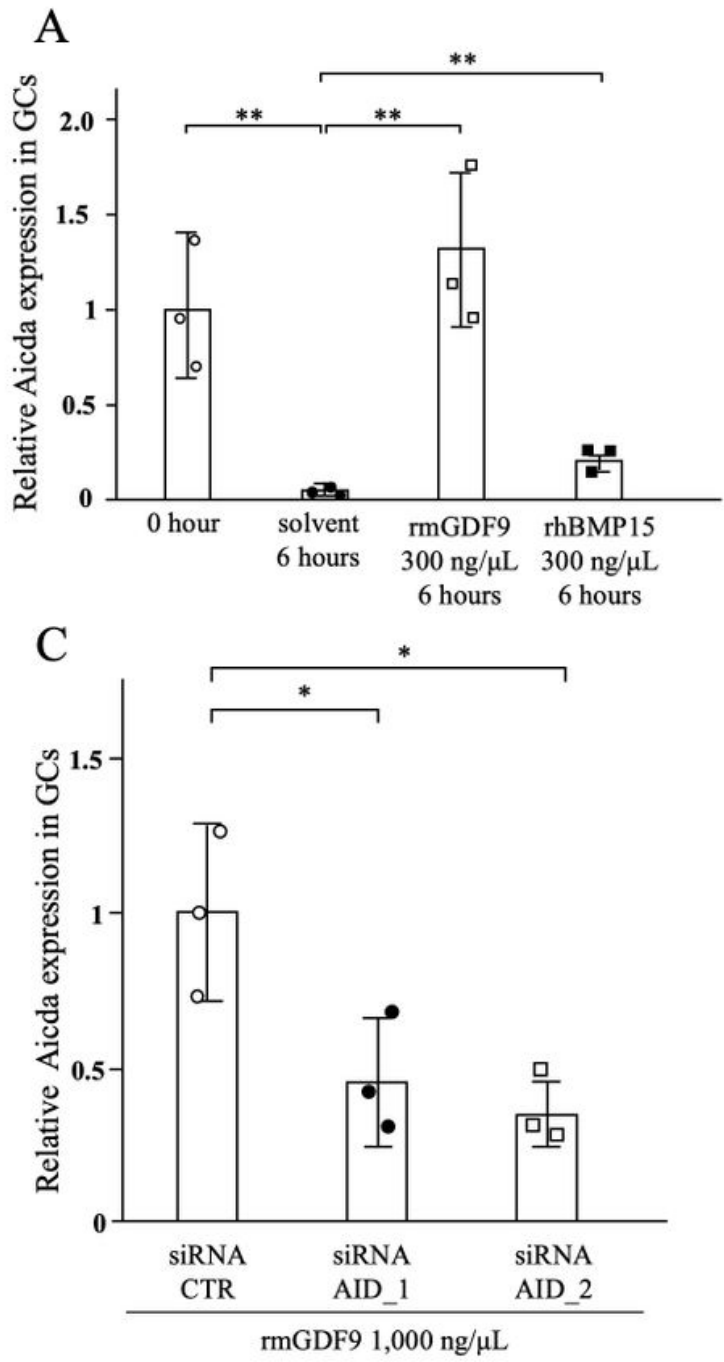
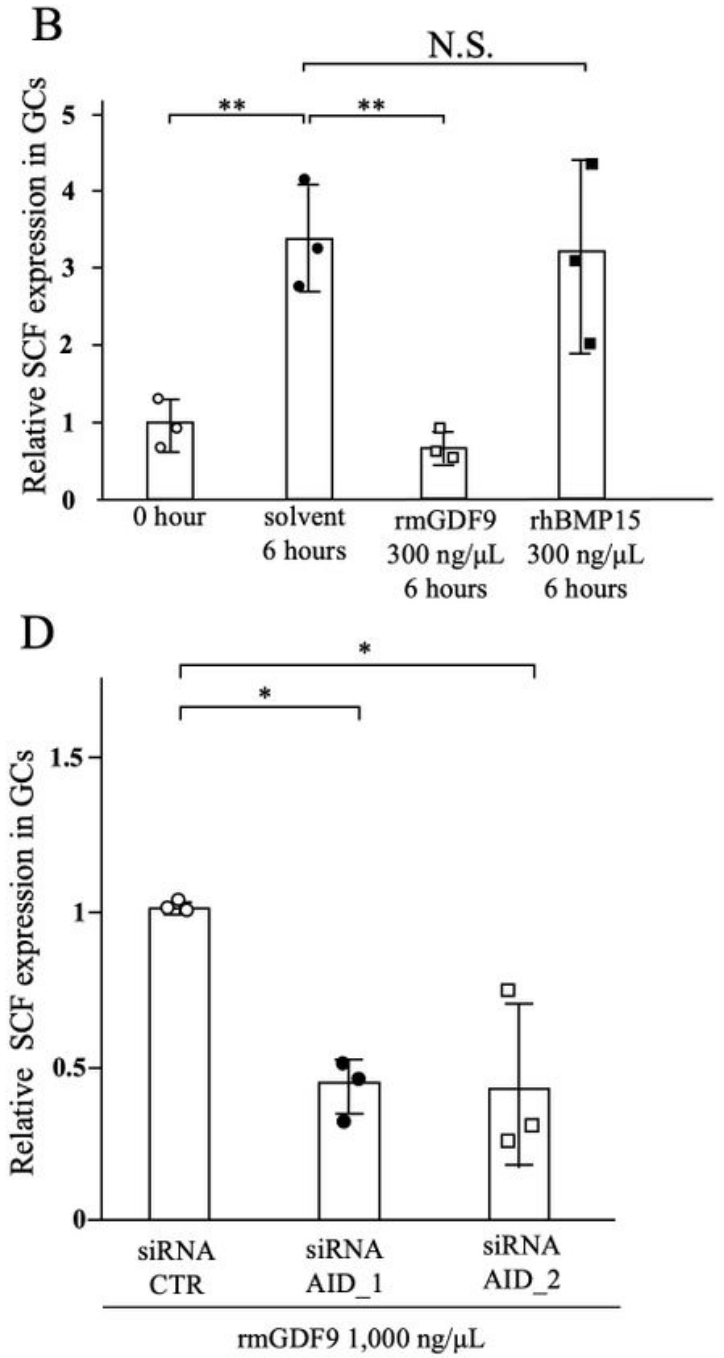

\section{Figure 5}

Regulation of SCF expression in cultured granulosa cells by GDF-9 and AID A-D. Granulosa cells isolated from the 3-week ovary of wild-type mice were subjected to the following culture experiments. AID and SCF expression relative to Gapdh in murine granulosa cells assessed by qPCR. A. AID expression was markedly decreased during a 6-hour culture. In contrast, AID expression was completely maintained in the presence of GDF-9. BMP-15 also showed enhancing effects on AID expression, but it recovered only a small part of the lost AID 1 expression. B. The mRNA expression of SCF was more than 3-times increased during a 6-hour culture. This increase was completely suppressed by GDF-9. BMP-15 showed no effects on SCF expression in cultured granulosa cells. C. In the presence of GDF-9, both siRNA-AID_1 and siRNAAID_2 significantly suppressed the mRNA expression of AID during a 48-hour culture. Under this condition, SCF expression was significantly reduced. *, $\mathrm{P}<0.05$; $\star \star, ~ P<0.01$. 
Fig.6
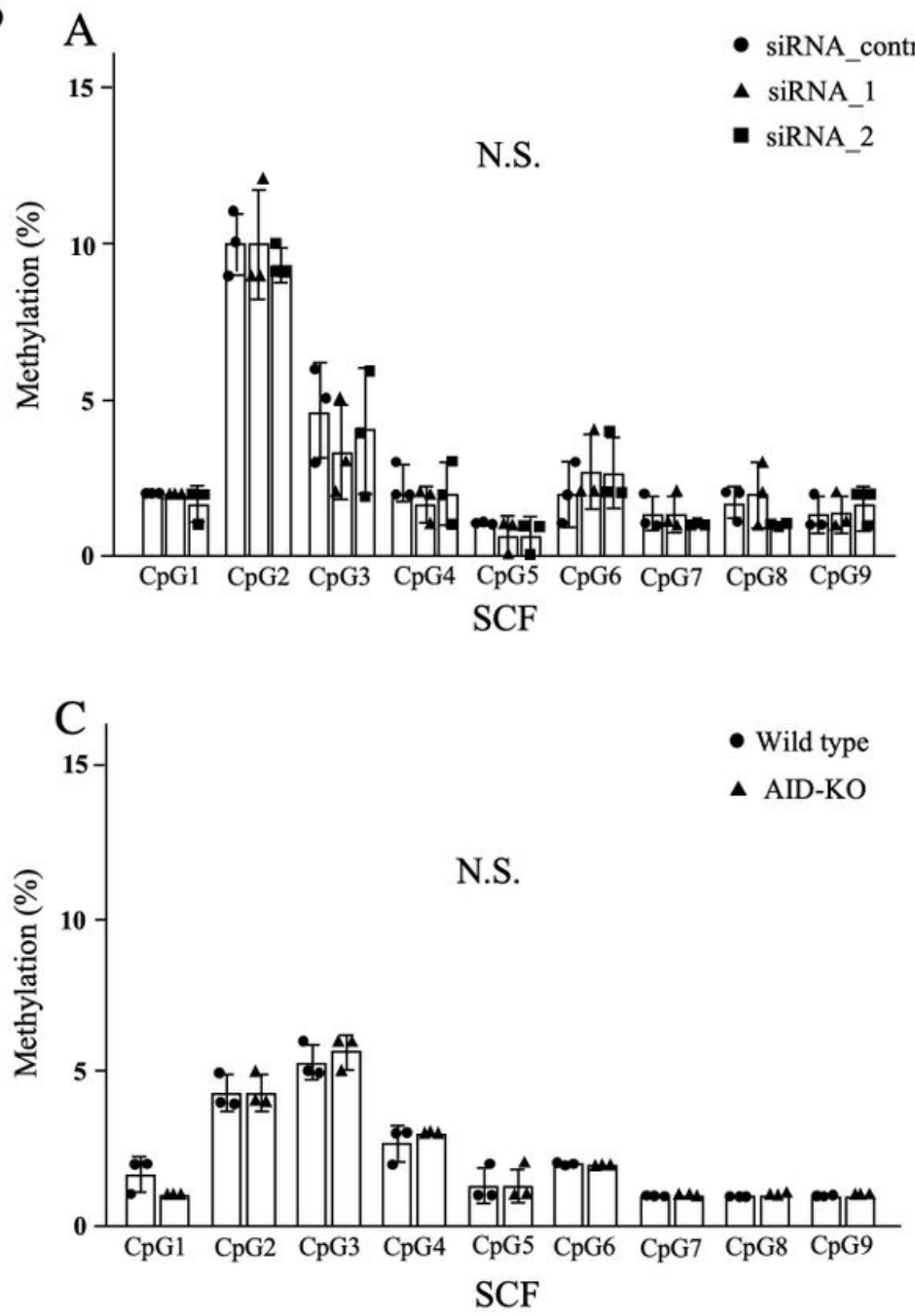

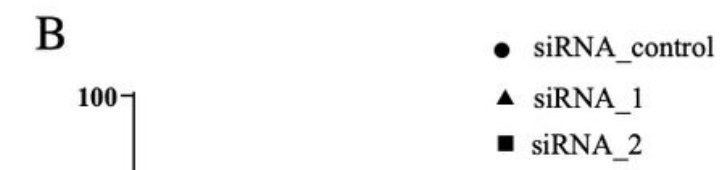

N.S.

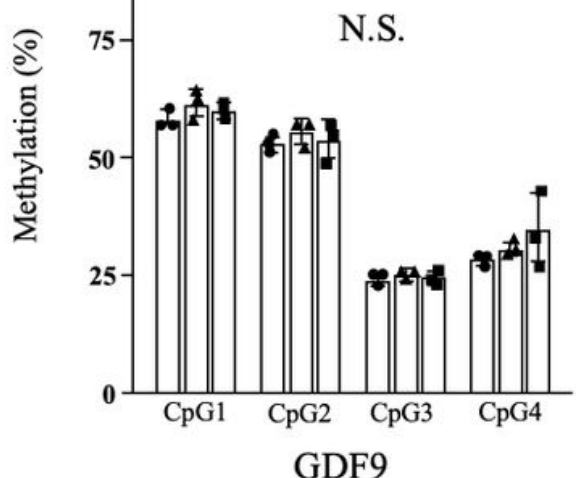

$\mathrm{D}$

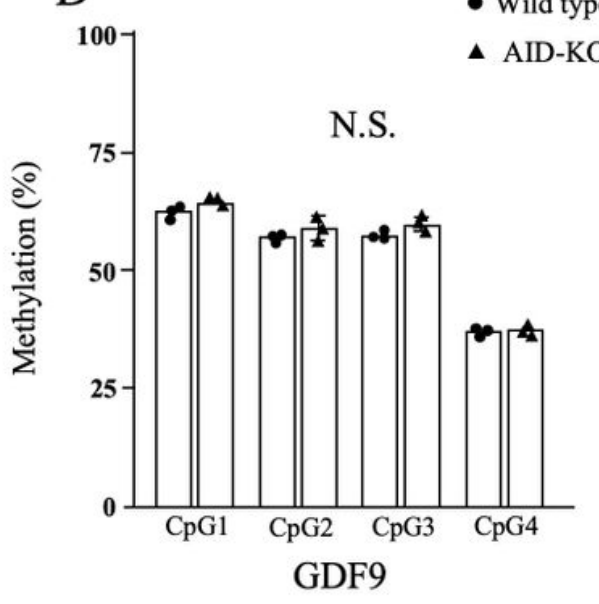

Figure 6

DNA methylation profiles of SCF and GDF-9 A-D. The DNA methylation profiles of SCF and GDF-9 using cultured granulosa cells ( $A$ and $B$ ) and ovarian tissues ( $C$ and $D$ ). In the granulosa cell culture, there were no significant differences in methylation profiles of SCF (A) and GDF-9 (B) among si-RNA-control, siRNA AID_1, and siRNA-AID_2 groups. There were also no differences in methylation profiles of SCF (C) and GDF-9 (D) in the ovarian tissues between wild-type and AID-KO mice.

\section{Supplementary Files}

This is a list of supplementary files associated with this preprint. Click to download.

- AIDpaperiizuka1113SupplementaryinformationSciRep.pdf

- lizukaetal.SupplementaryFig.1.jpg 